\title{
An In Situ Three-Point Bending Study on Pre-Notch 7075 Aluminium Alloy with Acoustic Emission
}

\author{
Pengliang Hou ${ }^{1}$, Zunqiang Fan $^{1}$, Lin Zhang ${ }^{2}$, Jianping $\mathrm{Li}^{1}$, \\ Haishuang $\mathrm{Fu}^{1}$, Lei $\mathrm{Han}^{1}$ and Hongwei Zhao ${ }^{1, *}$ \\ ${ }^{1}$ School of Mechanical Science and Engineering, Jilin University, Changchun 130025, China \\ ${ }^{2}$ Department of Integrated System Engineering, The Ohio State University, Columbus, U.S.A.
}

\begin{abstract}
Some types of congenital and machining-induced defects remain in a material, such as cracks and crack notches generated in a series of machining processes. Such structural defects will probably lead a reduction in the material's service life, and even a huge accident. It is important to investigate the influence of crack initiation, crack growth and crack failure in relation to the downgrading and failure of materials. We have employed the acoustic emission (AE) signal to identify the 7075 Aluminium alloy $(7075 \mathrm{Al})$ crack initiation and crack growth unilateral precrack, bilateral pre-cracks, unilateral V notch and bilateral V notches under three-point bending (TPB) conditions. At the same time the tip morphology of notch specimens is obtained by the opto-digital microscope. Comparing the in situ images with the AE signals, the results indicate that the AE signals can effectively predict the crack initiation, crack growth and crack rapid instability during TPB test. In addition, the geometrical shape of the specimen is relative to the intensity of AE signals. The AE signal of a no notch specimen is much higher than that of other notch specimens. The intensity of the AE signal of pre-crack specimens is lower than the V notch specimens. A pre-crack specimen causes failure more easily than the V notch specimen in the process of bending. Specimens with no notch, unilateral pre-crack, bilateral pre-cracks, unilateral $\mathrm{V}$ notch and bilateral $\mathrm{V}$ notches can be characterized by the intensity of AE signals. The position of the crack can be determined by the linear position of the AE signals. [doi:10.2320/matertrans.M2015279]
\end{abstract}

(Received July 9, 2015; Accepted September 1, 2015; Published November 25, 2015)

Keywords: acoustic emission (AE), pre-crack, V notch, in situ testing, three-point bending test (TPB)

\section{Introduction}

In the actual process of mechanical machining and production, due to various reasons, crack and crack notch are generally reminded in the finished products. The crack is generated by the coupling of fatigue, creep and corrosion, which can make the service materials invalidated. ${ }^{1)}$ The crack growth can cause huge losses to the national economy, or even threaten people's life. In the recent decades, in order to study the deformation materials mechanics behavior, three different forms of specimens are used, no notch, pre-crack and notch specimen. ${ }^{2-4)}$ No notch specimen and pre-crack are two extreme conditions of notch specimen. In other words, the opening angles of notch specimen ranges from 0 degree to 180 degrees. In previous studies, most cases mainly concentrated on the crack initiation, ${ }^{5,6)}$ crack propagation rate and fracture toughness, ${ }^{7,8)}$ the shape of notch and the radius of notch tip ${ }^{9,10)}$ the stress intensity factor and its distribution of notch tip ${ }^{11,12)}$ by the tension or three-point bending (TPB) or four-point bending (FPB).

In previous researches, acoustic emission (AE) is widely applied as a non-invasive method of monitoring the crack forming energy and crack extension in materials. ${ }^{13-15)} \mathrm{AE}$ collects the emission stress wave in a solid material which occurs when internal defects (or latent defects) under the action of applied stress automatically are generated. Therefore, deformation and crack propagation of the material is under the action of stress, which is the important deformation mechanism of the structure failure. The source is directly related to the deformation and fracture. Since the AE was firstly found by Kaiser in 1950s, the AE has been widely applied in engineering applications for internal defects and crack initiation, ${ }^{16,17)}$ fatigue life, ${ }^{18,19)}$ fracture location, ${ }^{20,21)}$ damage characterization ${ }^{22,23)}$ and evaluation the failure mechanisms and process. ${ }^{24,25)}$

In this paper, $\mathrm{AE}$ signals are employed to characterize three typical cases, the no notch, pre-crack and $\mathrm{V}$ notch specimens of $7075 \mathrm{Al}$ under TPB. The present paper aims to investigate the intensity of AE signals by the TPB on the notch specimens, and the relationship between the AE signals and the notch severity. Simultaneously, the tip morphology of notch specimens is in situ obtained by the opto-digital microscope during the TPB. Combining the in situ images with the AE signals, the results show that the AE signals can effectively detect the crack initiation, crack growth and crack rapid instability during TPB test. Moreover, the geometry of specimens is a very important factor on the intensity and amplitude of AE signals. The intensity and amplitude of AE signal increase significantly when the specimens undergo plastic deformation. The fracture location is detected by the AE sensors, which is consisted with the fracture location image that is in situ obtained by the opto-digital microscope.

\section{The Peak Load Ratio $\boldsymbol{P}_{\mathrm{B}} / \boldsymbol{P}_{\mathrm{U}}$}

The theoretical model of TPB is shown in Fig. 1. The notch specimen is placed on the supports, the punch contracts with the middle of point of it. During the bending, the notch is extended in $Y$ axis and at the same time the notch is sheared in the $Z$ axis. Therefore, the stress intensity factor (SIF) of tip notch is mixed mode (I+II)

$$
\begin{aligned}
& K=K_{\mathrm{I}}+K_{\mathrm{II}} \\
& K_{\mathrm{I}}=F_{\mathrm{I}} \sigma \sqrt{\pi a} \\
& K_{\mathrm{II}}=\frac{\tau \sqrt{\pi a}}{1-\frac{a}{W}}
\end{aligned}
$$




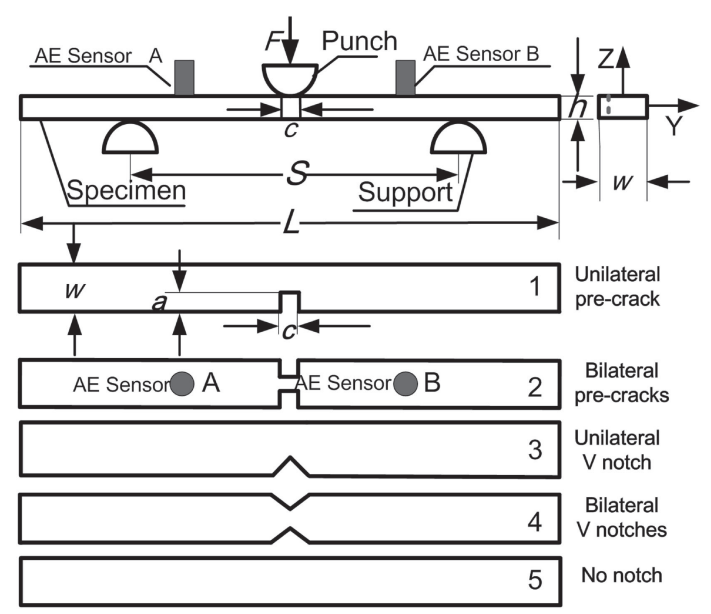

Fig. 1 The theoretical model of TPB and the type of specimens in the experiment.

$$
\tau=\frac{3 P}{2(W-a) h}, \quad \alpha=\frac{a}{W}, \frac{S}{2 W}=\frac{22}{12}>1
$$

The SIF $K_{\mathrm{I}}$ of unilateral pre-crack can be calculated by boundary collocation method ${ }^{26)}$

$$
F_{\mathrm{UC}}=1.12-0.23 \alpha+10.6 \alpha^{2}-21.7 \alpha^{3}+30.4 \alpha^{4}
$$

The SIF $K_{\mathrm{I}}$ of bilateral pre-cracks can be calculated by Bowie. $^{27)}$

$$
F_{\mathrm{BC}}=1.12+0.23 \alpha-1.197 \alpha^{2}+1.93 \alpha^{3}
$$

The SIF $K_{\mathrm{I}}$ of unilateral $\mathrm{V}$ notch can be calculated by Cole and Brow. ${ }^{28)}$

$$
F_{\mathrm{UV}}=0.953-3.255 \alpha+8.203 \alpha^{2}-4.85 \alpha^{3}
$$

The SIF $K_{\mathrm{I}}$ of bilateral V notches can be calculated by ling ${ }^{29)}$

$$
F_{\mathrm{BV}}=1.037-1.886 \alpha+0.649 \alpha^{2}+1.218 \alpha^{3}
$$

From the fracture mechanics, the ratio of peak load with the bilateral notches and unilateral notch $\left(P_{\mathrm{B}} / P_{\mathrm{U}}\right)$ according to the SIF is:

$$
\begin{aligned}
& \frac{3 P_{\mathrm{U}} S}{2 h^{\frac{3}{2}}} \times \sqrt{\alpha_{\mathrm{U}}} \times F_{\mathrm{U}}\left(\alpha_{\mathrm{U}}\right)+\frac{3 P_{\mathrm{U}}}{h(W-a)} \times \frac{\sqrt{\pi a}}{1-\alpha_{\mathrm{U}}} \\
& =\frac{3 P_{\mathrm{B}} S}{2 h^{\frac{3}{2}}} \times \sqrt{\alpha_{\mathrm{B}}} \times F_{\mathrm{B}}\left(\alpha_{\mathrm{B}}\right)+\frac{3 P_{\mathrm{B}}}{h(W-a)} \times \frac{\sqrt{\pi a}}{1-\alpha_{\mathrm{B}}} \\
& \frac{P_{\mathrm{B}}}{P_{\mathrm{U}}}=\frac{\frac{3 S}{2 h^{\frac{3}{2}}} \times \sqrt{\alpha_{\mathrm{U}}} \times F_{\mathrm{U}} \sqrt{\pi a}+\frac{3 W}{h(W-a)^{2}} \times \sqrt{\pi a}}{\frac{3 S}{2 h^{\frac{3}{2}}} \times \sqrt{\alpha_{\mathrm{B}}} \times F_{\mathrm{B}} \sqrt{\pi a}+\frac{3 W}{h(W-a)^{2}} \times \sqrt{\pi a}} \\
& \frac{P_{\mathrm{B}}}{P_{\mathrm{U}}}=\frac{2 h^{\frac{3}{2}}}{3 S} \times \sqrt{\alpha_{\mathrm{U}}} \times F_{\mathrm{U}}+\frac{3}{h\left(1-\alpha_{\mathrm{U}}\right)^{2}} \\
& 2 h^{\frac{3}{2}} \times \sqrt{\alpha_{\mathrm{B}}} \times F_{\mathrm{B}}+\frac{3}{h\left(1-\alpha_{\mathrm{B}}\right)^{2}}
\end{aligned}
$$

Where $a$ is the depth of the notch, $W$ is the width of the specimen, $h$ is the height of the specimen, $K, K_{\mathrm{I}}$ and $K_{\mathrm{II}}$ are the stress intensity factor, $S$ is the span of the supports, $F$ is the stress concentration factor, $P_{\mathrm{B}}$ is the peak load of bilateral notches specimen, $P_{\mathrm{U}}$ is the peak load of unilateral notch specimen.
Table 1 The chemical compositions of the $7075 \mathrm{Al}$ (mass\%).

\begin{tabular}{ccccccccc}
\hline $\mathrm{Si}$ & $\mathrm{Fe}$ & $\mathrm{Cu}$ & $\mathrm{Mn}$ & $\mathrm{Mg}$ & $\mathrm{Cr}$ & $\mathrm{Zn}$ & $\mathrm{Ti}$ & $\mathrm{AL}$ \\
\hline 0.4 & 0.5 & 1.6 & 0.3 & 2.6 & 0.24 & 5.6 & 0.2 & rest \\
\hline
\end{tabular}

Table 2 The type and sizes of notch specimen.

\begin{tabular}{ccccccc}
\hline List & Pre-crack & $\mathrm{c}(\mathrm{mm})$ & $\mathrm{a}(\mathrm{mm})$ & V notch & $\mathrm{c}(\mathrm{mm})$ & $\mathrm{a}(\mathrm{mm})$ \\
\hline 1 & Unilateral & 0.2 & 1.0 & Unilateral & 2.0 & 1.0 \\
2 & Unilateral & 0.2 & 2.0 & Unilateral & 2.0 & 2.0 \\
3 & Unilateral & 0.2 & 3.0 & Unilateral & 2.0 & 3.0 \\
4 & Unilateral & 0.2 & 4.0 & Unilateral & 2.0 & 4.0 \\
5 & Bilateral & 0.2 & 0.5 & Bilateral & 2.0 & 0.5 \\
6 & Bilateral & 0.2 & 1.0 & Bilateral & 2.0 & 1.0 \\
7 & Bilateral & 0.2 & 1.5 & Bilateral & 2.0 & 1.5 \\
8 & Bilateral & 0.2 & 2.0 & Bilateral & 2.0 & 2.0 \\
\hline
\end{tabular}

\section{Experiment}

\subsection{Specimens preparation}

The 7075 Aluminum alloy $(7075 \mathrm{Al})$ is used in this study. The $7075 \mathrm{Al}$ is a cold treatment forging alloy, high intensity, far more than mild steel. The $7075 \mathrm{Al}$ is widely employed in aerospace, automobile manufacturing, shipbuilding and other fields, due to its tight structure, strong corrosion resistant capability. The chemical composition of the $7075 \mathrm{Al}$ is given in Table 1. The specimen's dimension is $30 \mathrm{~mm} \times 6 \mathrm{~mm} \times$ $1 \mathrm{~mm}$. The specimens are cut by the electric discharge machining. This way can effectively eliminate the influence of pre-stress in the finished specimens. The specimens are divided into unilateral pre-crack, bilateral pre-cracks, unilateral $\mathrm{V}$ notch and bilateral $\mathrm{V}$ notches, no notch as shown in Fig. 1, $c$ is the width of notch, $a$ is the depth of notch, $W$ is the width of specimen, $h$ is the height of specimen. The size of notch is depicted in Table 2. Before the experiment, the specimens are ground sequentially with waterproof emery paper from 500-grit to 3000-grit manually, then polished with $50 \mathrm{~nm} \mathrm{SiO}_{2}$.

\subsection{The AE setting}

In this study, two 1283 USB AE nodes with 8 bit resolution, $20 \mathrm{MHz}$ sampling frequency are used that are made by Physical Acoustics Corporation (PAC). The USB AE node is a single channel AE digital signal processor with full $\mathrm{AE}$ hit and time-based features. The $\mathrm{AE}$ sensors are selected NANO-30 that working frequency ranges from $100 \mathrm{kHz}$ to $1000 \mathrm{kHz}$ and peak frequency is $288.09 \mathrm{kHz}$. The AEwin software is used for data acquisition, data processing and storage of the AE waveforms. A pencil lead of $0.5 \mathrm{~mm}$ diameter is employed to detect the threshold value of the $\mathrm{AE}$ sensors. It is found that the threshold value is $40 \mathrm{~dB}$ which can diminish the risk of environment noise interference to the AE signals. The control parameters of AE are set as shown in Table 3. The AE parameters applied to characterize all kinds of specimens in this study are: counts, amplitude, energy, duration time, rise time and peak frequency. The 2211 silicone compound as the coupling agent is used to enhance the $\mathrm{AE}$ 
Table 3 The AE control parameter settings.

\begin{tabular}{ccccc}
\hline Analog filter & Sample rate & PDT & HDT & HLT \\
\hline $200 \mathrm{k}-1 \mathrm{MHz}$ & $5 \mathrm{MHz}$ & $300 \mu \mathrm{s}$ & $600 \mu \mathrm{s}$ & $1000 \mu \mathrm{s}$ \\
\hline
\end{tabular}

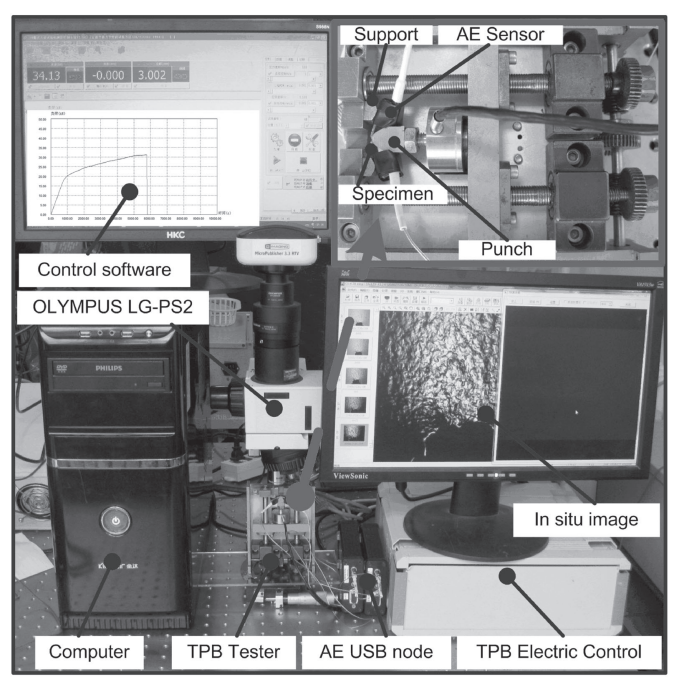

Fig. 2 The experimental system of TPB.

signals intensity. Before the experiment, two AE sensors are mounted in the both ends of the specimen by the coupling agent as shown in Fig. 1, and reinforced with the black tape. The same sensor fixation is used in all AE tests specimens.

\subsection{TPB test}

TPB is one of the most common used methods to investigate the mechanical performance of materials. The TPB test system is shown in Fig. 2, including USB AE nodes, data acquisition and processing, electrical control, control software, opto-digital microscope (OLYMPUS LGPS2) and the in situ TPB tester. The AE signals of specimen are sampled by two USB AE nodes during the bending. The TPB tester is controlled by the electrical control and control software. The data acquisition and processing are served by the computer. The tip morphology of notch specimen surface is in situ obtained by the opto-digital microscope during the TPB. The TPB tester is served in the experiment, calibrated by the Agilent G200 nanoindenter. The distance of supports is $22 \mathrm{~mm}$. The punch radius is $3 \mathrm{~mm}$. During the bending, the flexure load and flexure deflection are recorded automatically. The flexure load is obtained from the force sensor. The flexure deflection is gained from the motor encoder that has been calibrated by the KEYENCE LK-G10 laser displacement sensor. The resolution of the laser displacement sensor is $10 \mathrm{~nm}$.

In the experiments, the specimens fixing the AE sensors are placed on the supports vertically to ensure that the punch is contacted with the center of specimens. Displacement controlled method is selected and the loading rate is $1 \mu \mathrm{m} / \mathrm{s}$. The notch tip morphology is in situ obtained by opto-digital microscope during the specimen bending. At the same time, the AE signals are sampled by two USB AE nodes during the specimens bending. The bending deflection is $3 \mathrm{~mm}$ in each

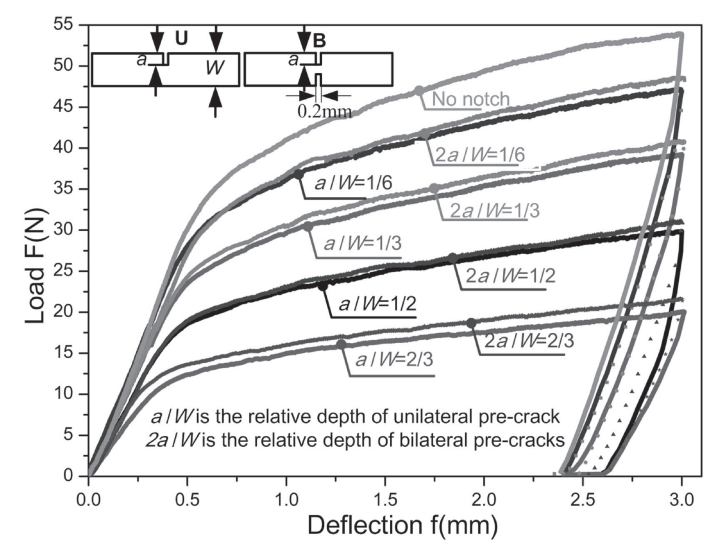

Fig. 3 The load-deflection curves of no notch, unilateral pre-crack notch and bilateral pre-cracks with different the relative depth $a / W$.

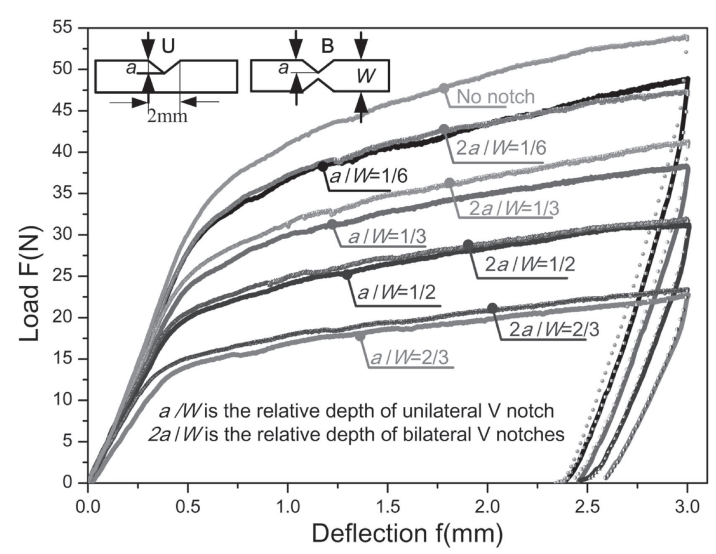

Fig. 4 The load-deflection curves of no notch, unilateral $\mathrm{V}$ notch and bilateral $\mathrm{V}$ notches with different the relative depth $a / W$.

time at room temperature. As the specimens are bent, the inner surface (the punch contact surface) is compressed and the outer surface is stretched.

\section{Results}

\subsection{The relative depth $a / W$ of notch influence the peak load}

The load-deflection curves are obtained on the $7075 \mathrm{Al}$ no notch, the unilateral pre-crack and bilateral pre-cracks notch specimens with the relative depth $a / W$ as shown in Fig. 3. In Fig. 4 shows the load-deflection curves gain about the $7075 \mathrm{Al}$ the unilateral $\mathrm{V}$ and bilateral $\mathrm{V}$ notches specimens with the relative depth $a / W$. The peak loads and yield limits of no notch specimens are far more than that of the notch specimens. The peak load and yield limit of unilateral notch specimens are smaller than that of the bilateral notches specimens.

\subsection{AE results}

During the TPB test, the AE signal parameters of the no notch and notch specimens are obtained by two AE USB nods. The relative depth of unilateral pre-crack and unilateral $\mathrm{V}$ notch specimens is $a / W=2 / 3$. The bilateral pre-cracks and bilateral $\mathrm{V}$ notches specimens are selected as the relative depth $2 a / W=2 / 3$. The statistics of AE parameters with the notch specimens are given in Table 4 . The hit and energy of 
Table 4 The statistic of all type of specimens AE parameters.

\begin{tabular}{ccrrrr}
\hline Sample & Type & Hit & Event & \multicolumn{1}{c}{ Count } & Energy \\
\hline 1 & & 205 & 12 & 2409 & 3329 \\
2 & BPre-cracks & 241 & 10 & 2860 & 3524 \\
3 & & 198 & 8 & 2217 & 3210 \\
\hline 4 & & 278 & 17 & 4736 & 7602 \\
5 & UPre-crack & 269 & 16 & 4527 & 7143 \\
6 & & 286 & 19 & 5159 & 7854 \\
\hline 7 & & 1389 & 8 & 9286544 & 2015786 \\
8 & BV notches & 1490 & 5 & 9698221 & 2150413 \\
9 & & 1578 & 12 & 9854162 & 2545984 \\
\hline 10 & & 2351 & 10 & 25678941 & 8547894 \\
11 & UV notch & 2525 & 11 & 28903267 & 8906653 \\
12 & & 2489 & 10 & 27854213 & 8677811 \\
\hline 13 & & 75894 & 52 & 35126871 & 15894723 \\
14 & No notch & 79669 & 59 & 36382463 & 16910589 \\
15 & & 78654 & 57 & 35125185 & 16822158 \\
\hline
\end{tabular}

no notch specimen are much higher than that of other notches specimens. The hit, count and energy of $\mathrm{V}$ notch specimens are much higher than that of pre-crack specimens.

In engineering practice, the materials failure experiences three stages: crack initiation (I), crack propagation (II) and crack instability of fast fracture (III). In this study, the specimens only have two stages I and II. Considering the theory of metal microscopic fracture, the fracture process of metals is circulated with the I, II and III. Therefore, the AE signal amplitude varies with the failure process. The AE amplitude, counts, energy, peak frequency, duration time and rise time are affected by the metal microscopic structure changing. During the TPB test, the AE counts/duration time ratio of no notch and notch specimens is sampled by the $\mathrm{AE}$ USB nod as shown in Fig. 5. The AE counts/duration time ratio of no notch specimen is distributed from 0.005 to 0.03 . The AE counts/duration time ratio of no notch specimen is much higher than that of notch specimens. When the AE counts/duration time ratio of no notch specimen is 0.01 , the $\mathrm{AE}$ counts/duration time ratio got to its peak during the bending. With the same relative depth $a / W=2 / 3$ and $2 a / W=2 / 3$, the AE counts/duration time ratio of $\mathrm{V}$ notch specimen is much more than that of pre-crack specimen. And the AE counts/duration time ratio of bilateral notches specimen is much lower than that of unilateral notch specimen. Thus, the shape of specimen is a key factor on the number of $\mathrm{AE}$ counts/duration time ratio.

Due to the relative depth $a / W=2 / 3$ and $2 a / W=2 / 3$ of specimens in the TPB process, the amplitude of AE signals is waved with the rise time as shown in Fig. 6. The AE amplitude of no notch specimen is much higher than that of other notch specimens when the rise time is about $800 \mu \mathrm{s}$. The amplitude of $\mathrm{V}$ notch specimen is lower than that of the pre-crack specimen. The AE amplitudes of no notch specimen are particularly wide ranging from $36 \mathrm{~dB}$ to $68 \mathrm{~dB}$. The $\mathrm{AE}$ amplitudes of pre-crack specimen range from $40 \mathrm{~dB}$ to $66 \mathrm{~dB}$. The $\mathrm{AE}$ amplitudes of $\mathrm{V}$ notch specimens range from $42 \mathrm{~dB}$ to $67 \mathrm{~dB}$. The rise time of no notch and $\mathrm{V}$ notch specimen is distributed in the range of $0-12500 \mu \mathrm{s}$. However,

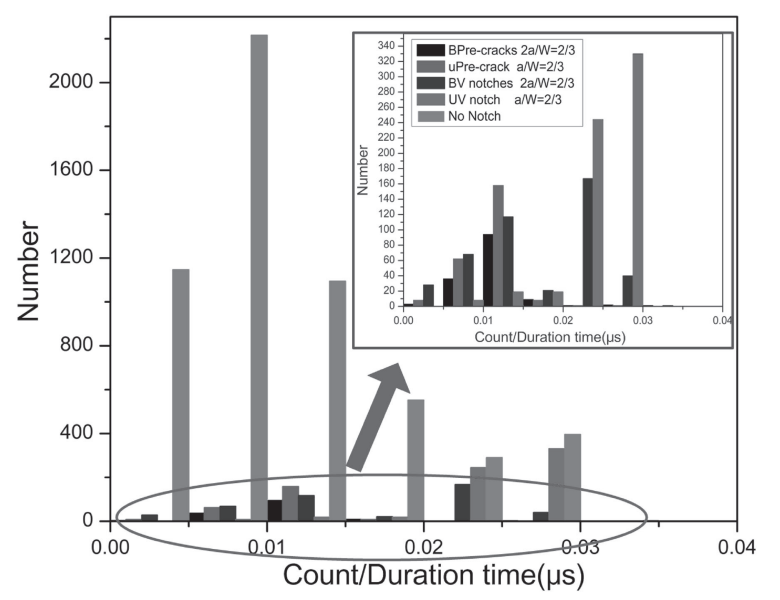

Fig. 5 The AE count of no notch and notch specimens during the TPB.

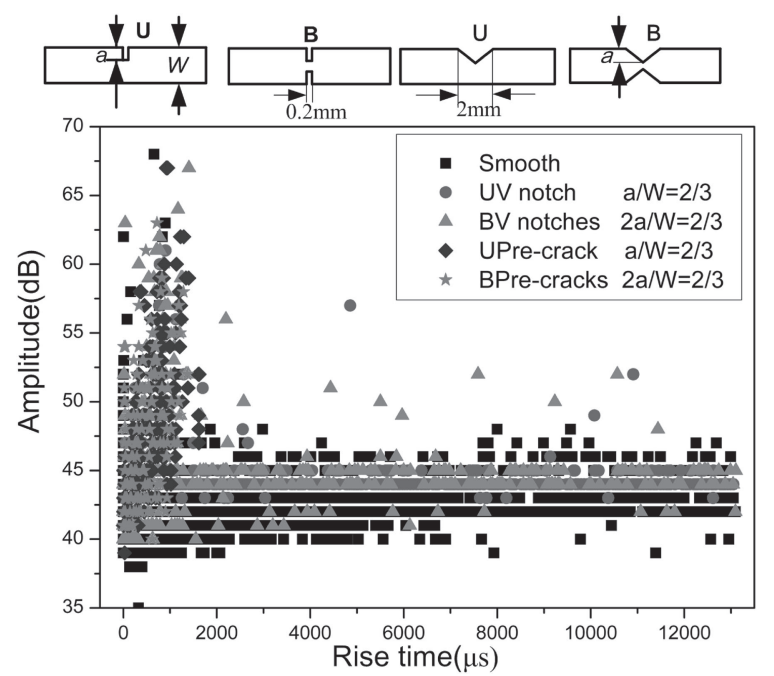

Fig. 6 The AE amplitude of no notch and notch specimens during the TPB.

the rise time of pre-crack is distributed in the range of 0 $1800 \mu \mathrm{s}$. Therefore, the shape of specimen is a very important factor on the level of the AE amplitude. This result consists with the conclusion of Aggelis. ${ }^{30)}$

The AE peak frequency of no notch and notch specimens is shown in Fig. 7. The peak frequency of no notch specimen is much higher than that of the notch specimens. The peak frequency of bilateral pre-cracks specimen is much bigger than that of unilateral pre-crack specimen. The peak frequency of bilateral $\mathrm{V}$ notches specimen is lower than that of unilateral $\mathrm{V}$ notch specimen. The peak frequency of precrack specimen is distributed in the range of $0-1500 \mathrm{kHz}$. However, the peak frequency of $\mathrm{V}$ notch specimen is distributed in the range of $0-27500 \mathrm{kHz}$.

\subsection{In situ images acquisition}

The opto-digital microscope is used to in situ acquire the tip morphology of notch specimens during the TPB, when the bending deflection is $0.5 \mathrm{~mm}, 1.0 \mathrm{~mm}$ and $3.0 \mathrm{~mm}$, respectively. The relative depth of unilateral pre-crack and bilateral pre-cracks is $a / W=2 / 3$ and $2 a / W=2 / 3$, respectively. The process of crack initiation, crack growth and crack propagation is recorded. According to the Fig. 8, it is noted that the 


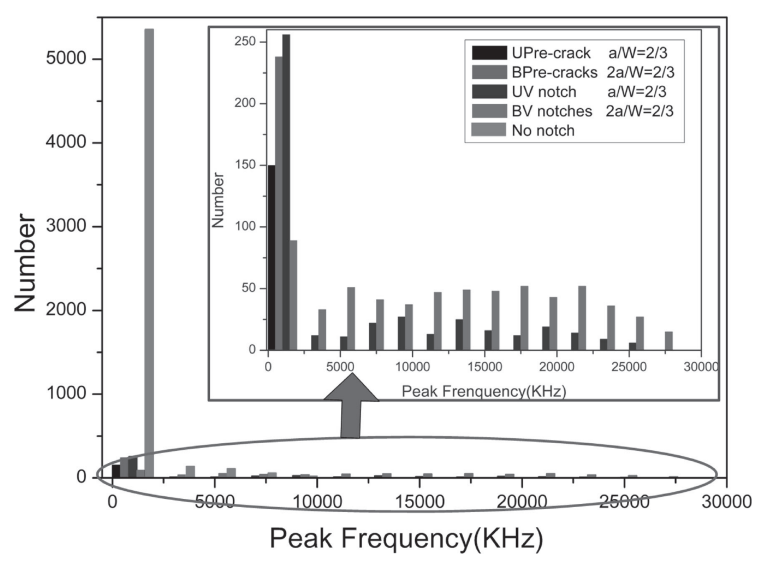

Fig. 7 The peak frequency distribution of no notch and notch specimens during the TPB.
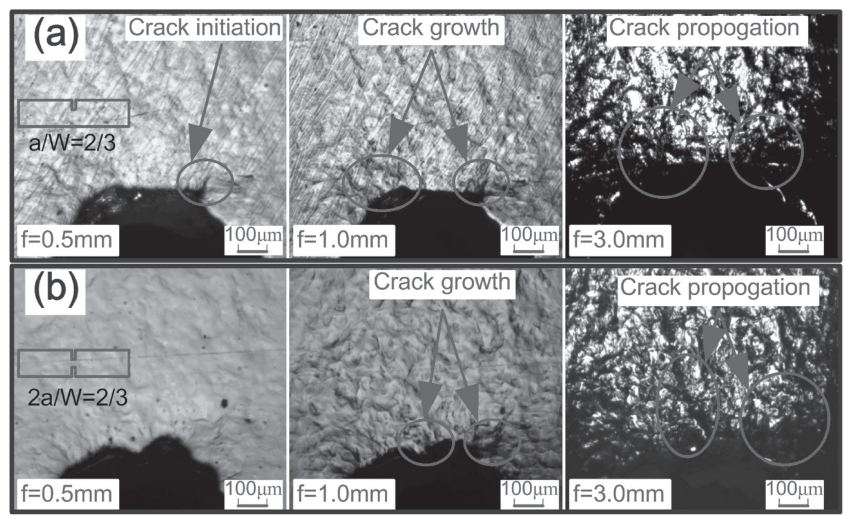

Fig. 8 The in situ images of crack initiation, crack growth and crack propagation with unilateral pre-crack and bilateral pre-cracks specimens under TPB

crack initiation of unilateral pre-crack at the deflection is $0.5 \mathrm{~mm}$. However, the crack initiation of the bilateral precrack generates at the deflection is $0.7 \mathrm{~mm}$. The length of crack growth with the bilateral pre-cracks specimens is shorter than that of the unilateral pre-crack specimens. The longer the crack length is, the lower the stress of crack initiation is. In addition, the tip morphology of the bilateral pre-crack specimen changes much less than that of the unilateral precrack specimens by contrasting the above images.

Figure 9 shows the tip morphology in situ images of the unilateral $\mathrm{V}$ notch and bilateral $\mathrm{V}$ notches, when the bending deflection is $0.5 \mathrm{~mm}, 1.0 \mathrm{~mm}$ and $3.0 \mathrm{~mm}$, respectively. When the relative depth of unilateral $\mathrm{V}$ notch and bilateral $\mathrm{V}$ notches is $a / W=2 / 3$ and $2 a / W=2 / 3$, the tip morphology of unilateral $\mathrm{V}$ notch specimen is deformed than that of bilateral V notches specimen. This result is in agreement with the results obtained in Fig. 4. The peak load of unilateral V notch specimen is less than that of bilateral $\mathrm{V}$ notches specimen, when the bending deflection is the same.

\section{Discussion}

\subsection{The relative depth $a / W$ effects on the peak load ratio $\boldsymbol{P}_{\mathrm{B}} / \boldsymbol{P}_{\mathrm{U}}$}

For the notch specimens, the relative depth $a / W$ is a very important factor during the TPB tests. When the relative
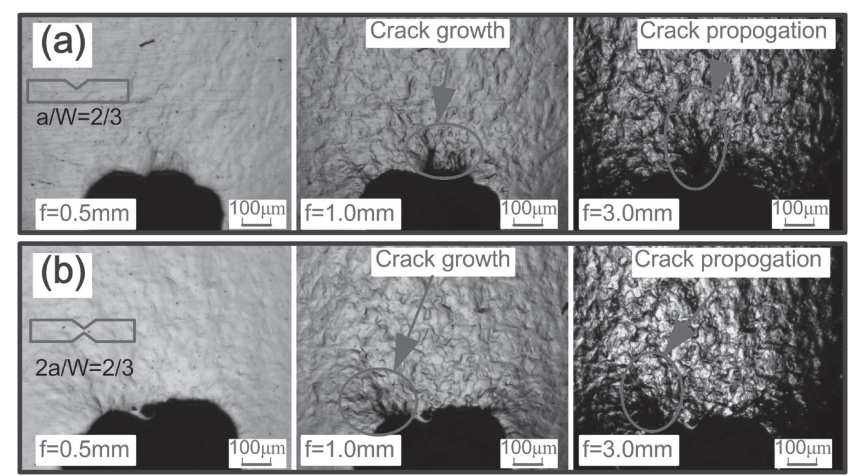

Fig. 9 The in situ images of crack initiation, crack growth and crack propagation with unilateral $\mathrm{V}$ notch and bilateral $\mathrm{V}$ notches specimens under TPB.

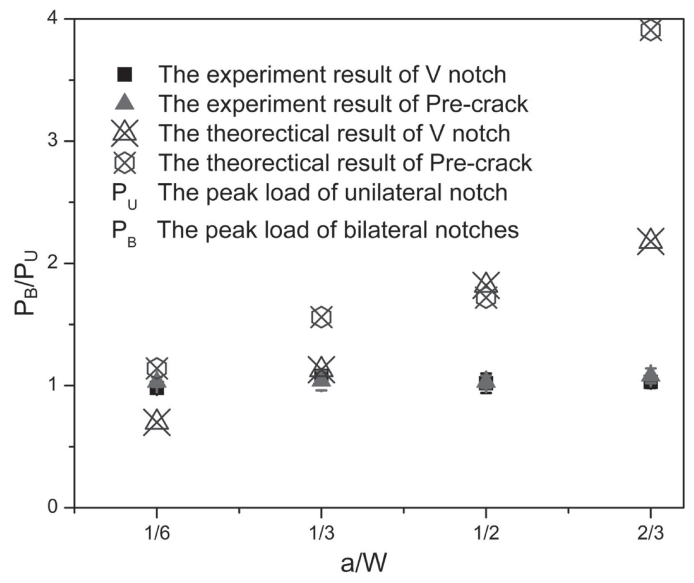

Fig. 10 The relationship between the peak load ratio $P_{\mathrm{B}} / P_{\mathrm{U}}$ and the relative depth $a / W$ of notch specimens.

depth $a / W$ is substituted into eq. (10), the change of relative depth $a / W$ directly affects on the peak load ratio $P_{\mathrm{B}} / P_{\mathrm{U}}$ of notch specimen. As shown in Fig. 10, the theoretical calculation peak load ratio $P_{\mathrm{B}} / P_{\mathrm{U}}$ of all the specimens is increased with the relative depth $a / W$ increasing, while the peak load ratio $P_{\mathrm{B}} / P_{\mathrm{U}}$ of $\mathrm{V}$ notches specimen is less than that of the pre-crack specimens. The experiment peak load ratio $P_{\mathrm{B}} / P_{\mathrm{U}}$ is about 1 . When the relative depth of $a / W$ is from $1 / 6$ to $2 / 3$, the peak load ratio $P_{\mathrm{B}} / P_{\mathrm{U}}$ is only a small fluctuation. When the relative depth of $a / W$ is less than $1 / 3$, the peak load ratio $P_{\mathrm{B}} / P_{\mathrm{U}}$ of the experiment is similar to that of the theoretical calculation. However, the peak load ratio $P_{\mathrm{B}} / P_{\mathrm{U}}$ of the theoretical calculation is much more than that of the experiment, with the relative depth of $a / W=2 / 3$. Therefore, it can be considered that when the relative depth ratio $a / W$ exceeded $2 / 3$, it is no meaning for practical engineering application.

\subsection{Relationship between the AE signal and in situ image}

During the TPB tests, the AE signals and in situ images are recorded at the same time by two AE USB nods and optodigital microscope, respectively. The comparison between the $\mathrm{AE}$ energy and the in situ images is shown in Fig. 11. In the stage II, the amplitude and intensity of AE energy signals is much higher than that of stage I. The AE energy of no notch 


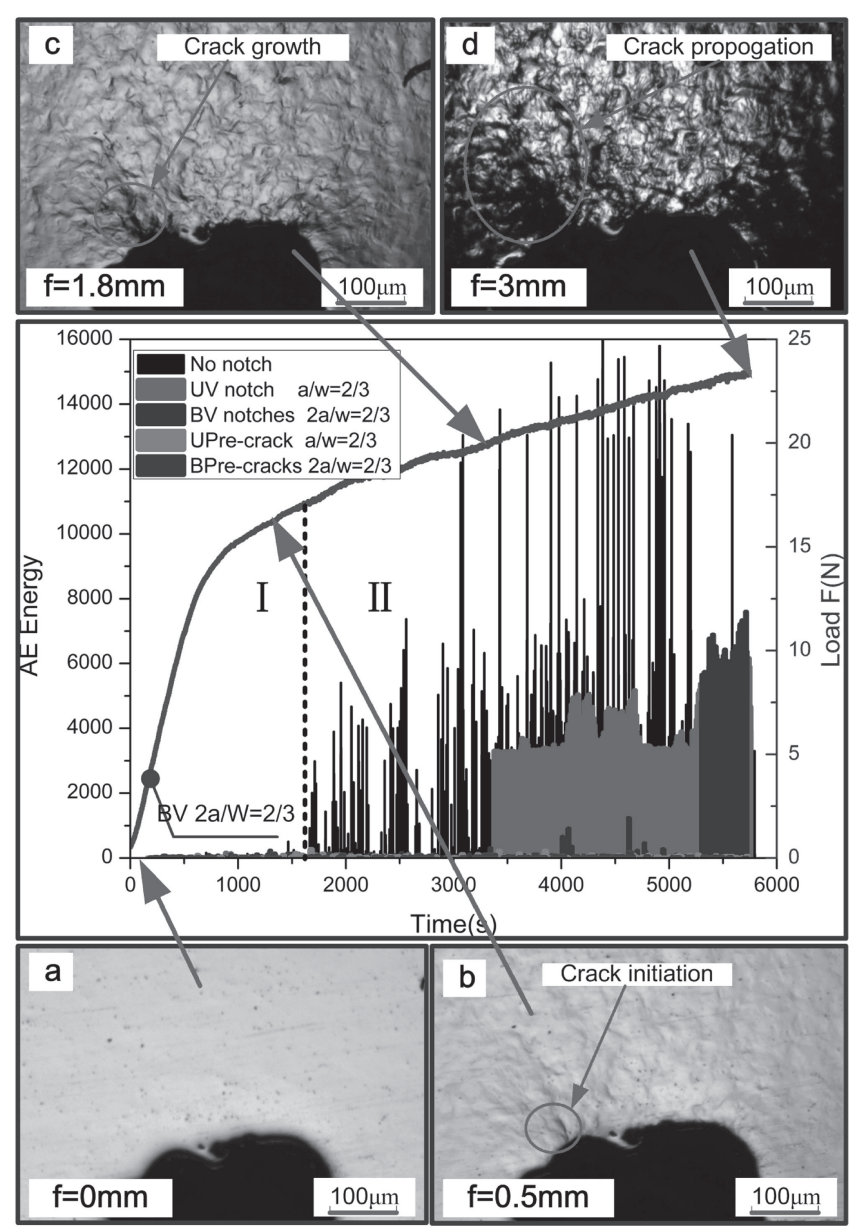

Fig. 11 The characterization of the crack initiation and crack propagation by the AE energy signal.

specimen is far more than that of the notch specimens. The AE energy of pre-crack notch specimens is much lower than that of the $\mathrm{V}$ notch specimens. In order to verify the accuracy of the AE signal acquisition, the tip morphology of the bilateral $\mathrm{V}$ notches specimen with the relative depth $a / W=2 / 3$ is in situ recorded during the bending of TPB tests. In the Fig. 11(a), it is the tip morphology of bilateral V notches specimen at the deflection of $0.0 \mathrm{~mm}$. At this time, the AE energy is little. It is not the $\mathrm{AE}$ signals but the interfering signals to cause this phenomenon. Because the specimen has not deformed, the signal is generated from the surrounding environment, such as the punch and supports. During the three point bending process, a large number of internal dislocations, slips and shear bands are generated inside the specimens. The crack initiation is formed by the broken of shear band as shown in Fig. 11(b). At the same time, it inspires a small certain amount of AE energy signals, which are very weak. The new crack is produced by the dislocation, slip and shear bands continuously formed during further bending. Due to continuous convergence of crack, the length of crack is continuous extension as shown in the Fig. 11(c). The surface morphology of bilateral V notch specimen has undergone serious changes, and then the number of cracks increases. Simultaneously, the number of AE energy signals also increases. ${ }^{31)}$ With the continuous bending of the specimen, a large numbers of shear bends are broken. At the same time, a lot of AE signals are inspired.

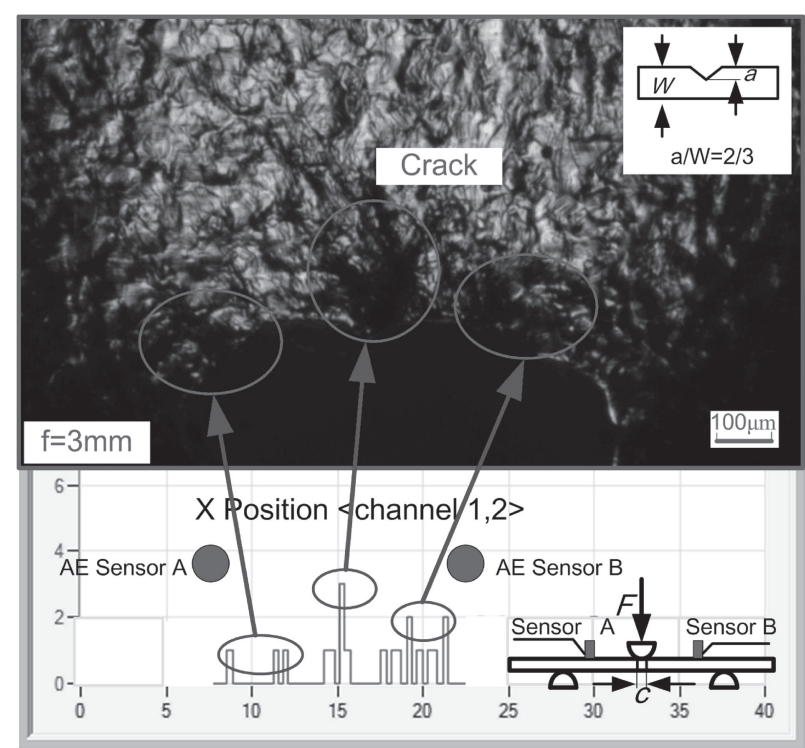

Fig. 12 The AE result of the crack position compares with the in situ image.

The density of AE energy signals is increased. The tip surface morphology of the specimen further damages, new cracks continue to generate and converge, and the length of the crack further extend as shown in Fig. 11(d). In this process, the peak of energy is continuously rising. ${ }^{32)}$

By comparing the linear positioning results of $\mathrm{AE}$ with the in situ image, it is found that they are consistent with each other as shown in Fig. 12. Where the crack is generated, the more the acoustic emission signals are excited. Therefore, the position of the crack can be detected by the linear position of the AE signal.

Accordingly, the specimen shape is a very significant factor for the $\mathrm{AE}$ count, $\mathrm{AE}$ peak frequency, $\mathrm{AE}$ amplitude, $\mathrm{AE}$ energy, $\mathrm{AE}$ duration time and $\mathrm{AE}$ rise time during the TPB tests. The AE parameters can effectively characterize the extent of the metal deformation. And at the same time, the damage mechanisms can be detected according to the amplitude and intensity of AE parameters change. ${ }^{33,34)}$ All $\mathrm{AE}$ parameters of no notch specimen are much higher than that of other notch specimens. The position of the crack can be determined by the linear position of the acoustic emission signal.

\section{Conclusions}

In this paper, the specimens of no notch, unilateral and bilateral notches are investigated by the $\mathrm{AE}$ parameters during the TPB tests. Meanwhile the tip morphology of notch specimens is recorded by the opto-digital microscope. The maximum deflection of the middle point is $3.0 \mathrm{~mm}$. By comparing the AE parameters with the in situ images, conclusions can be drawn as the following:

(1) No matter what kind of notch specimen is, the peak load decreases with the relative depth $a / W$ rising. The peak load of bilateral notches specimens is higher than that of the unilateral notch specimens.

(2) It is a crucial factor that the geometry of specimen impacts on the intensity of the AE signals. By 
comparing the notch specimens with the no notch specimens, it is found that they exhibit differences in the AE signals intensity. The AE signals intensity of no notch specimen is much higher than that of other notch specimens. The AE signals intensity of pre-crack specimen is lower than the $\mathrm{V}$ notch specimen.

(3) By comparing the AE signals with the in situ images of the tip morphology, it is found that the intensity and amplitude of AE signal can effectively characterize the crack initiation and crack growth. The position of the crack can be determined by the linear position of the acoustic emission signal.

\section{Acknowledgments}

This research is funded by the National Natural Science Foundation of China (Grant Nos. 51275198), Special Projects for Development of National Major Scientific Instruments and Equipments (Grant No. 2012YQ030075), and Program for New Century Excellent Talents in University of Ministry of Education of China (Grant No. NCET-12-0238), Specialized Research Fund for the Doctoral Program of Higher Education (Grant No. 20130061110026), Patent Demonstration Project for Research Team in Jilin Province (Grant No. 20130416015ZG).

\section{REFERENCES}

1) N. E. Dowling: Mechanical Behavior of Materials, (Prentice Hall, Englewood Cliffs, NJ, 1993).

2) M. A. Meyers and K. K. Chawla: Mechanical Behavior of Materials, Vol. 2 (Cambridge: Cambridge University Press, 2009) pp. 420-425.

3) G. E. Dieter and D. Bacon: Mechanical Metallurgy, Vol. 3 (New York, McGraw-Hill, 1986) pp. 260-261.

4) T. H. Courtney: Mechanical Behavior of Materials, (Waveland Press, 2005) pp. 404-454.

5) S. Saxena and N. Ramakrishnan: Int. J. Pressure Vessels Pip. 84 (2007) 493-501.

6) Q. Yang and J. Luo: Bulletin Electrochemistry 17 (2001) 18-23.

7) I. Marines-Garcia, P. C. Paris and H. Tada: Int. J. Fatigue 29 (2007)
2072-2078.

8) A. Noroozi, G. Glinka and S. Lambert: Eng. Fracture Mech. 75 (2008) 188-206.

9) F. Berto, P. Lazzarin, A. Kotousov, et al.: Fatigue Fract. Eng. M. 35 (2012) 538-555.

10) M. P. Savruk and A. Kazberuk: Int. J. Fracture 161 (2010) 79-95.

11) R. Afshar, F. Berto and P. Lazzarin: J. Strain Anal. Eng. Des. 48 (2013) 291-305.

12) P. Lazzarin, M. Zappalorto and F. Berto: Int. J. Fracture 170 (2011) $123-144$.

13) B. Raghu Prasad and R. Vidya Sagar: J. Mater. Civil Eng. 20 (2008) 212-220.

14) H. Zejli, L. Gaillet and A. Laksimi: J. Bridge Eng. 17 (2012) 921-927.

15) H. Su, J. Hu, J. Tong and Z. Wen: Ultrasonics 52 (2012) 890-904.

16) C. Mukhopadhyay, T. Jayakumar and T. Haneef: Int. J. Pressure Vessels Pip. 116 (2014) 27-36.

17) J. P. Tronskar, M. A. Mannan and M. O. Lai: J. Test. Eval. 31 (2003) 222-233.

18) D. Shan and H. Nayeb-Hashemi: J. Mater. Sci. 34 (1999) 3263-3273.

19) M. Bourchak, I. Farrow and I. Bond: Int. J. Fatigue 29 (2007) 457-470.

20) G. Jones, S. Nippress and A. Rietbrock: Pure Appl. Geophys. 165 (2008) 235-254.

21) J.-M. Park, J.-W. Kong, J.-W. Kim and D.-J. Yoon: Compos. Sci. Technol. 64 (2004) 983-999.

22) A. Bussiba, M. Kupiec, S. Ifergane, et al:: Compos. Sci. Technol. 68 (2008) 1144-1155.

23) B.-L. Yang and X. Yan: Nondest. Test. Eval. 24 (2009) 251-260.

24) A. Karl, S. Cunis, R. Gehrke, G. V. Krosigk, U. Lode, I. Luzinov, S. Minko, T. Pomper, V. Senkovsky, A. Voronov and W. Wilke: J. Macromol. Sci.-Physics 38 (1999) 901-912.

25) S. Minko, A. Karl and V. Senkovsky: J. Macromol. Sci.-Physics 38 (1999) 913-929.

26) B. Gross, J. E. Srawley and W. F. Brown Jr.: Stress-intensity factors for a sigle-edge-notch tension specimen by boundary collocation of a stress function (No. NASA-TN-D-2395). (National Aeronautics and Space Administration Cleveland Oh Lewis Research Center, 1964.) pp. 1-11.

27) O. L. Bowie: J. Appl. Mech. 31 (1964) 208.

28) H. Neuber: Theory of Notch Stresses, (JW Edwards, 1946).

29) C. B. Ling: J. Appl. Mech. 35 (1968) 833-835.

30) D. G. Aggelis: Mech. Res. Commun. 38 (2011) 153-157.

31) D. Aggelis, A. Mpalaskas and T. Matikas: Mech. Res. Commun. 47 (2013) 39-43.

32) T. Shiotani, K. Fujii, T. Aoki and K. Amou: Progress in Acoustic Emission 7 (1994) 529-534.

33) S. Huguet, N. Godin, R. Gaertner and L. Salmon: Compos. Sci. Technol. 62 (2002) 1433-1444.

34) B. Chen and J. Liu: Cement Concrete Res. 34 (2004) 391-397. 